\title{
Erratum to: Analysis of Full Volterra and Sparse Volterra Nonlinear Equalization for Downlink LTE System
}

\author{
Nasreddine Mallouki ${ }^{1}$ Bechir Nsiri ${ }^{1}$ Sofien Mhatli ${ }^{2}$. \\ Mohammad Ghanbarisabagh $^{3} \cdot$ Walid Hakimi $^{1}$ • \\ Mahmoud Ammar ${ }^{1}$
}

(C) Springer Science+Business Media New York 2016

\section{Erratum to: Wireless Pers Commun DOI 10.1007/s11277-016-3325-6}

The list of authors was incomplete in the initial online publication. The online publication has been updated to address this omission, and the list of authors is now correct in the article (and in this erratum).

The online version of the original article can be found under doi:10.1007/s11277-016-3325-6.

Mohammad Ghanbarisabagh

m.ghanbarisabagh@gmail.com

1 Sys'comLab, ENIT, BP.37, 1002 Le Belvédère, Tunis, Tunisia

2 SERCOM-Labs, EQPT Université de Carthage, 2078 La Marsa, Tunis, Tunisia

3 Faculty of Engineering, Islamic Azad University North Tehran Branch, Tehran, Iran 